\title{
Correlations between osteoartritis grading in femorotibial joint (kellgren lawrence) with cartilage defects grading
}

\author{
Yuliati Permatasari ${ }^{1}$, Nasirun Zulqarnain ${ }^{1}$, Hermina Sukmaningtyas ${ }^{1}$, Bantar Suntoko ${ }^{2}$
}

${ }^{1}$ Radiology Department, Faculty of Medicine, Diponegoro University, Semarang ${ }^{2}$ Internal Medicine Department, Faculty of Medicine, Diponegoro University, Semarang

Corespondence: Yuliati Permatasari, MD Dipenogoro Street II, Pati, Center Java email :

yuliatipermatasari@ rocketmail.com

\begin{abstract}
Background : Osteoarthritis $(\mathrm{OA})$ is the most common chronic rheumatic diseases that causing pain and disability. The imaging of knee OA were found in 15,5\% men and $12,7 \%$ women of Indonesia population. Radiography is still used as a standard modalities in assesing $0 \mathrm{~A}$ progression, and Kellgren-Lawrence scale $(\mathrm{KL})$ is the most common measurement used by clinicians. Superficial cartilage degradation is the first sign of $\mathrm{OA}$, the early detection of the superficial cartilage degradation is very important for diagnosis. Our study was established to assess the correlation between $\mathrm{OA}$ grading in femorotibial joint examined by standard Kellgren-Lawrence scale (KL) measurement with cartilage defects examined by ultrasound.

Methods : Observational analytic study with cross sectional and consecutive sampling was performed. Rank Spearman test for correlation of OA grading, cartilage defect, BMl and joint malalignment. McNemar test for correspondence between the location of the narrowing of the femorotibial joint and location of cartilage defects.
\end{abstract}

Result : Correlation of OA grading of femorotibial joints $(K L)$ with cartilage defects grading on ultrasound resulted $r=0.459, p<0.05$; correlation of $0 \mathrm{~A}$ grading of femorotibial joints $(\mathrm{KL})$ with $\mathrm{BMI}$ or joint malalignment resulted $p>0,05$; correlation of cartilage defect grading with BMI or joint malalignment also resulted $p>0.05$. McNemar test for location of the narrowing of the femorotibial joint with location of cartilage defects on ultrasound resulted $p=1.00, k=0.714$. There was a significant positive correlation of $\mathrm{OA}$ grading of femorotibial joints (KL) with cartilage defects grading on ultrasound. There was no significant correlation between $\mathrm{OA}$ grading of femorotibial joints (KL) with $\mathrm{BMI}$ and joint malignment, and no significant correlation between cartilage defects grading with $\mathrm{BMI}$ and joint malalignment. There is a correspondence between the location of the narrowing of the femorotibial joint with location of cartilage defects on ultrasound.

Conclusion: For assesing the grade of osteoartritis, cartilage defect grading and assesment by ultrasound can be used as an alternative to X-Ray KellgrenLawrence scale (KL) measurement.

Keywords : femorotibial joint, cartilage defects grading, osteoartritis grading examination, BMI, joint malalignment.

\section{Background}

Osteoarthritis (OA) is a chronic rheumatic diseases most frequently encountered and causes pain and disability. It is a degenerative joint disease, which encountered the joints that support the body weight. ${ }^{1-3}$ Some special characteristics that could be found in OA, include: the erosion of cartilage, bone hypertrophy (osteophytes), subchondral sclerosis, as well as biochemical and morphological changes in the synovial membrane and joint capsule. ${ }^{4}$

The prevalence of knee OA in Indonesia reached $15.5 \%$ in men and $12.7 \%$ in women. ${ }^{5}$ In Prof. Dr. R. D. Kandou Hospital, during the month of March 1994 until November 1995, the prevalence of OA reached out $36.81 \%$. OA is the highest cases (37\%) among all arthritis cases in our hospital, and knee OA account for $97 \%$ of all OA patients. ${ }^{6}$

The knee joint has three compartments, among others: femorotibial lateral, femorotibial medial and femoropatela. ${ }^{3}$ Process biochemistry involving cartilage, bone and synovial can damage all compartments of the knee joint. ${ }^{3,7}$ Some risk factors of OA, include age, heredity, joint malalignment, obesity, metabolic diseases and trauma to the joint. Each factor contributes to the pathogenesis of early and advanced OA disease.,

Radiography is still the standard assessment of OA progression, and scale of Kellgren-Lawrence $(\mathrm{KL})$ is the most common radiographic modality used by clinicians..$^{8-10}$ However, ultrasound can be used to detect an early manifestation of osteoartritis abnormalities in patients with osteoarthritis. $^{8}$ OA disrupts the collagen network, declines the proteoglycans, increases the water content, and results mechanical changes in joint cartilage. ${ }^{11}$ Trauma to the collagen network leads the development of an advanced OA. ${ }^{12}$ Superficial degradation of cartilage is an early sign of OA. Therefore, the early detection of the superficial cartilage degradation is very important for diagnosing OA. ${ }^{13}$ If the early changes can be diagnosed properly, disease progression can be declined with medication intervention and lifestyle changes. ${ }^{14}$ Therefore, we aim to assess the correlation between OA grading in femoropatella joint by Kellgren Lawrence scale measurement with cartilage defects grading by ultrasound examination. 


\section{Methods}

Observational analytic study with crosssectional and consecutive sampling was performed for this study. Data that is analyzed, includes charateristics of subjects (age, level of work, and BMI); OA grading by X-Ray examination; cartilage defect grading by ultrasound assesment. Grading of OA is done using Kellgren-Lawrence (KL) score. Grading of cartilage defect by ultrasound assesment is done using International Cartilage Repair Society classification. Level of work is measured based on Mathenson LN classification. WOMAC score is used to asses any pain, rigidity and disability. Subjects are classified based on Likert scale: (0) no symptoms; (1) mild symptoms; (2) moderate symptoms; (3) severe symptoms; and (4) very severe symptoms. Rank Spearman test are done for assesing the correlation of OA grading with cartilage defect, $\mathrm{BMI}$ and joint malalignment, respectively. McNemar test are done to search any correspondence between the narrowing location of the femorotibial joint and the location of cartilage defects.

\section{Result}

Forty-three samples were included as respondents in this study. Respondents age range from 41 to 77 years old, with an average of 57,8 years old. Portion of group age is dominated by group of 50-59 years old, which account for 17 people (39,5\%). Women account for 72,1\% (33 people). Samples grouped as "heavy work", classified by Matheson LN, were as much as 21 people (48.8\%). Most BMI value at the level of overweight and obesity as much as $22(51.2 \%)$. Characteristics of study subjects, such as: age, weight, job, BMI, OA grading, cartilage defect grading, malalignment, and WOMAC scores can be seen in Table 1.

Table 1 Subjects Characteristics

\begin{tabular}{cccc}
\hline \multicolumn{1}{c}{ Characteristics } & \multicolumn{2}{c}{ Gender $\mathbf{N}(\%)$} & Total \\
& Man & female & $\mathbf{N}(\%)$ \\
\hline Age Group & $2(28.6)$ & $5(71.4)$ & $7(16.3)$ \\
$40-49$ & $4(23.5)$ & $13(76.5)$ & $17(39.5)$ \\
$50-59$ & $3(21.4)$ & $11(78.6)$ & $14(32.6)$ \\
$60-69$ & $3(60.0)$ & $2(40.0)$ & $5(11.6)$ \\
$70-79$ & & & \\
Level of work & $0(0)$ & $12(100)$ & $12(27.9)$ \\
Light & $7(33.3)$ & $14(66.7)$ & $21(48.8)$ \\
moderate & $3(50.0)$ & $3(50.0)$ & $6(14.0)$ \\
Weight & $2(50.0)$ & $2(50.0)$ & $4(9.3)$ \\
Very heavy & & & \\
BMI & $6(28.6)$ & $15(71.4)$ & $21(48.8)$ \\
Normoweight & $6(27.3)$ & $16(72.7)$ & $22(51.2)$ \\
Overweight and obesity & & & \\
0A grading & $2(28.6)$ & $5(71.4)$ & $7(16.3)$ \\
1 & $10(37.0)$ & $17(63.0)$ & $27(62.8)$ \\
2 & $0(0)$ & $5(100)$ & $5(11.6)$ \\
3 & $0(0)$ & $4(100)$ & $4(9.3)$ \\
4 & & &
\end{tabular}

\section{Cartilage defect grading}

$\begin{array}{lccc}0 & 6(75.0) & 2(25.0) & 8(18.6) \\ 1 & 2(11.8) & 15(88.2) & 17(39.5) \\ 2 & 1(33.3) & 2(66.7) & 3(7.0) \\ 3 & 2(16.7) & 10(83.3) & 12(27.9) \\ 4 & 1(33.3) & 2(66.7) & 3(7.0) \\ \text { ignment } & & & \\ \text { ormal } & 10(30.3) & 23(69.7) & 33(76.7) \\ \text { arus } & 0(0) & 3(100) & 3(7.0) \\ \text { Valgus } & 2(28.6) & 5(71.4) & 7(16.3) \\ \text { AC score } & & & \\ \text { A 1 } & & & 1.636 \\ \text { OA 2 } & & & 1.188 \\ \text { OA 3 } & & & 1.265 \\ \text { OA 4 } & & & 1.383\end{array}$

Normoweight: BMI $\left(18,5-25 \mathrm{~kg} / \mathrm{m}^{2}\right)$; obesity and overweight: BMI $\left(>25 \mathrm{~kg} / \mathrm{m}^{2}\right)$

Majorly samples have grade $2^{\text {nd }} \mathrm{OA}$, measured in 27 people $(62.8 \%)$, with the number of women 17 people $(63.0 \%)$. The median value of the OA grading for both men and women is the same, grade 2, as presented in Figure 1.

Figure 1 Boxplot $0 A$ degrees of subjects by sex.

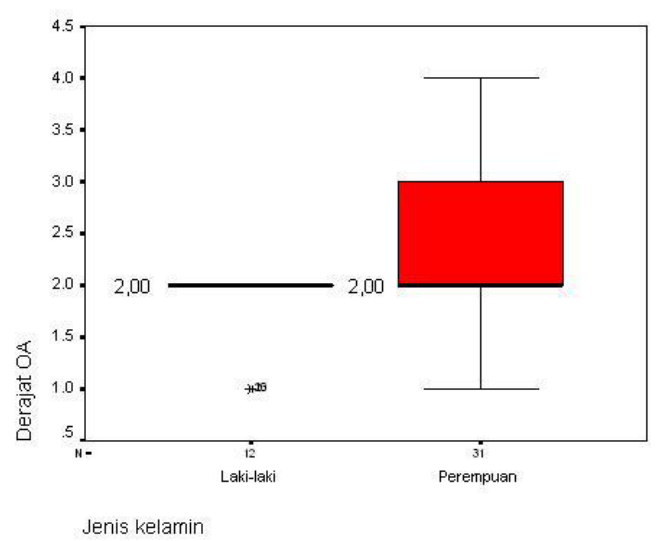

Analysis of the relationship between OA grading of femorotibial joints with BMI, showed no significant relationship $(p>0.05)$. The median BMI of samples whose have grade $3^{\text {rd }} \mathrm{OA}$ and grade $4^{\text {th }} \mathrm{OA}$ were $26.37 \mathrm{~kg} / \mathrm{m}^{2}$ and $27.66 \mathrm{~kg} / \mathrm{m}^{2}$, respectively, as seen in Table 2 .

Table 2 Correlation of femorotibia joint OA grading and BMI

\begin{tabular}{|c|c|c|c|c|c|}
\hline \multirow[t]{2}{*}{ BMI } & \multicolumn{4}{|c|}{ OA grading of femorotibia joint } & \multirow[t]{2}{*}{ p value } \\
\hline & 1 & 2 & 3 & 4 & \\
\hline $18.5-25 \mathrm{~kg} / \mathrm{m}^{2}$ & $4(57.1)$ & $15(55.6)$ & $2(40.0)$ & $0(0)$ & 0.199 \\
\hline$>25 \mathrm{~kg} / \mathrm{m}^{2}$ & $3(42.9)$ & $12(44.4)$ & $3(60.0)$ & $4(100)$ & \\
\hline
\end{tabular}

Group as normoweight (BMl 18.5-25 kg/m²) and overweight/ obesity (BMI $>25 \mathrm{~kg} / \mathrm{m}^{2}$ )

From the measurement of femorotibial angle at the knee joint, samples obtained normal alignment account for 33 
joints (76.7\%), with median value $4^{\circ}$ valgus; valgus alignment account for 7 joints $\left(16.3 \%\right.$ ), with median value $11.5^{\circ}$ valgus; and varus alignment account for 3 joints (7.0\%), with median value $4.5^{\circ}$ varus. The boxplot is shown in Figure 2 .

Figure 2. Boxplot of femorotibia joints malaligment

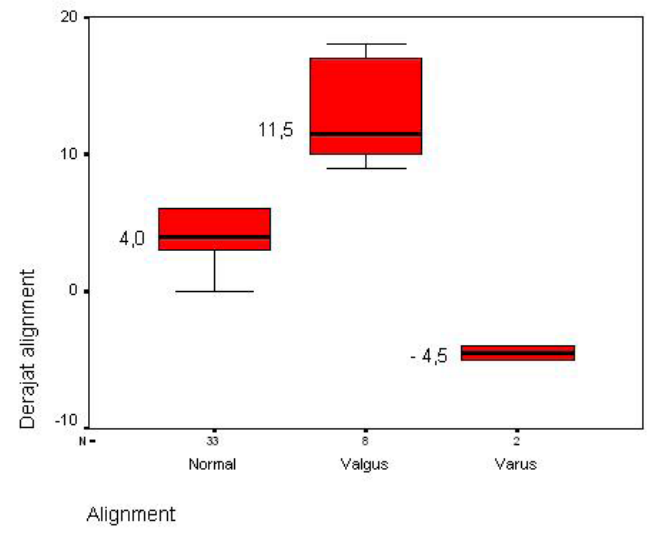

Correlation analysis of OA grading and malignment in femorotibial joints is showed in Table 3. Our study resulted no significant relationship ( $p>0.05)$ between OA grading and malalignment in femorotibial joint. The $1^{\text {st }}$ grade OA have median malalignment value of $6^{\circ}$ valgus, the $2^{\text {nd }}$ grade OA have median malalignment value of $5^{\circ}$ valgus, $3^{\text {rd }}$ grade OA have median malalignment value of $3^{\circ}$ valgus, and the $4^{\text {th }}$ grade OA have median malalignment value of $8.8^{\circ}$ valgus.

Table 3 Correlations OA grading of femorotibia joint with malalignment

\begin{tabular}{lccccc}
\hline & \multicolumn{4}{c}{ OA grading of femorotibia joint } & \multirow{2}{*}{$p$ value } \\
\cline { 2 - 5 } & 1 & 2 & 3 & 4 & \\
\hline Malalignment & $2(28.6)$ & $4(14.8)$ & $2(40.0)$ & $2(50.0)$ & 0.311 \\
No Malalignment & $5(71.4)$ & $23(85.2)$ & $3(60.0)$ & $2(50.0)$ & \\
\hline
\end{tabular}

The mean WOMAC score of the samples is classified as mild to moderate class. The median WOMAC score of $1^{\text {st }}$ grade $\mathrm{OA}, 2^{\text {nd }}$ grade $\mathrm{OA}, 3^{\text {rd }}$ grade $\mathrm{OA}$, and $4^{\text {th }}$ grade $\mathrm{OA}$ are $1.4,1.1,1.4$ and 1.3 , respectively, as shown in figure 3 .

Figure 3 Boxplot of WOMAC scores and OA grading

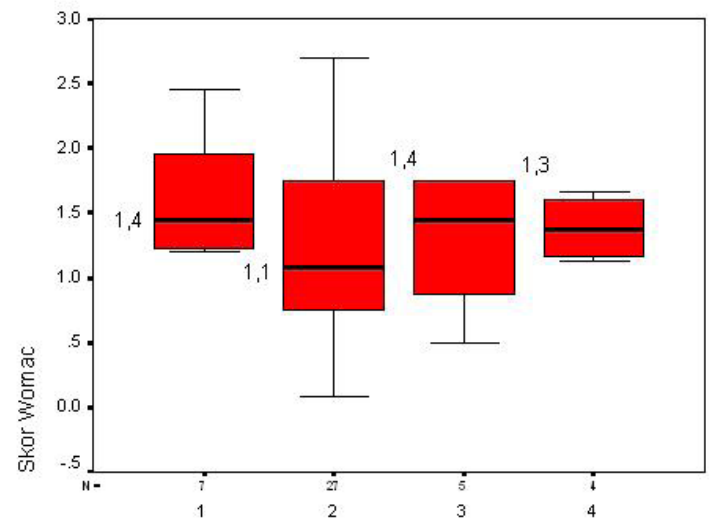

Derajat $\mathrm{OA}$
Most cartilage defects were found in the $1^{\text {st }}$ grade $\mathrm{OA}$, which were examined in 17 subjects $(39,5 \%)$, and 15 subjects $(88,2 \%)$ of them were female. The median value cartilage defect degrees for men is 0.5 and for women is 1 , as presented in figure 4.

Figure 4 Boxplot of cartilage defects degrees by sex

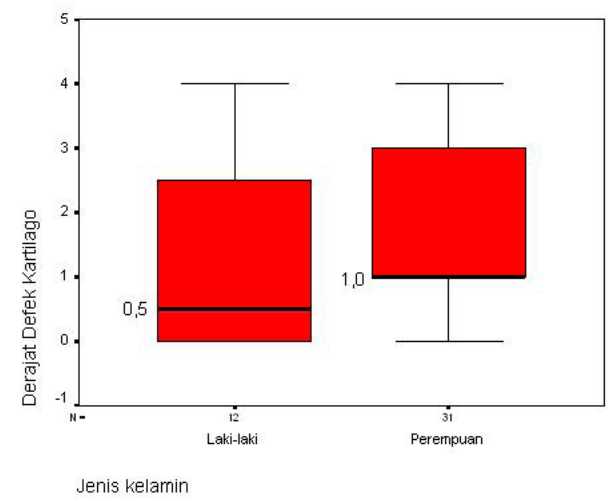

BMI had no significant relationship with cartilage defect $(\mathrm{p}>0,05)$, as presented in table 4 . Subjects with cartilage defect grading as 0 have average BMI of $26,7 \mathrm{~kg} / \mathrm{m}^{2}$, which classified as overweight. Subjects with cartilage defect grading as second, third, and fourth, have average BMI of $31.6 \mathrm{~kg} / \mathrm{m}^{2}$; $26.6 \mathrm{~kg} / \mathrm{m}^{2} ; 26.3 \mathrm{~kg} / \mathrm{m}^{2}$, respectively.

Table 4 Correlations cartilage defects grading with BMI

\begin{tabular}{|c|c|c|c|c|c|c|}
\hline \multirow[t]{2}{*}{ BMI } & \multicolumn{5}{|c|}{ Cartlage defects grading } & \multirow[t]{2}{*}{ p value } \\
\hline & 0 & 1 & 2 & 3 & 4 & \\
\hline $18,5-25 \mathrm{~kg} / \mathrm{m}^{2}$ & $3(37.5)$ & $12(70.6)$ & $1(33.3)$ & $4(33.3)$ & $1(33.3)$ & 0.252 \\
\hline$>25 \mathrm{~kg} / \mathrm{m}^{2}$ & $5(62.5)$ & $5(29.4)$ & $2(66.7)$ & $8(66.7)$ & $2(66.7)$ & \\
\hline
\end{tabular}

The relationship of cartilage defect grading with malalignment showed no significant relationship ( $>0.05$ ), as shown in table 5 . The median value of alignment in subjects with no cartilage defect were $6^{\circ}$ valgus; in subjects with first grade cartilage defect were $4^{\circ}$ valgus; in subjects with second grade cartilage defects were $5^{\circ}$ valgus; in subjects with third grade cartilage defects were $3.5^{\circ}$ valgus; and in subjects with fourth degree cartilage defects were $0^{\circ}$ valgus.

Table 5 Correlations cartilage defects grading with malalignment

\begin{tabular}{lcccccc}
\hline & \multicolumn{5}{c}{ Cartlage defects grading } & p \\
\cline { 2 - 6 } & $\mathbf{0}$ & $\mathbf{1}$ & $\mathbf{2}$ & $\mathbf{3}$ & $\mathbf{4}$ & value \\
\hline Malalignment & $2(25.0)$ & $3(17.6)$ & $1(33.3)$ & $3(25.0)$ & $1(33.3)$ & 0.954 \\
No Malalignment & $6(75.0)$ & $14(82.4)$ & $2(66.7)$ & $9(75.0)$ & $2(66.7)$ & \\
\hline
\end{tabular}

The thickness of the cartilage had an average value of 0.18 $\mathrm{cm}$ on the medial side; $0.20 \mathrm{~cm}$ on the trochlear, and $0.17 \mathrm{~cm}$ on the lateral side. The median value of cartilage thickness of KL 3 was $0.20 \mathrm{~cm}, 0.15 \mathrm{~cm}$, and $12.09 \mathrm{~cm}$ for medial side, trochlear, and lateral side, respectively. The median value of cartilage thickness of KL 4 at medial side was $12.05 \mathrm{~cm}$, the trochlear was $0.26 \mathrm{~cm}$, lateral side was $0.19 \mathrm{~cm}$.

We found a strong correlation between the location of cartilage defect assesed by USG and the location of narrowing 
femorotibia joint measured by $\mathrm{x}$-ray imaging, McNemar test resulted $\mathrm{p}>0.05$ and kappa scored 0.714 , as seen in table 6 .

Table 6 Allocation of cartilage defect (by USG) and narrowing femorotibia joints (by X-Ray)

\begin{tabular}{lccc}
\hline $\begin{array}{l}\text { Location narrowing on } \\
\text { X-Ray medial }\end{array}$ & \multicolumn{2}{l}{$\begin{array}{l}\text { Location defect Ultrasound } \\
\text { lateral }\end{array}$} \\
\hline Medial & $\mathrm{N}(\%)$ & $5(62.5 \%)$ & $1(12,5 \%)$ \\
Lateral & $\mathrm{N}(\%)$ & $0(0 \%)$ & $2(25 \%)$ \\
\hline
\end{tabular}

$p$ value $=1,000 ;$ kappa $=0,714$

Rank Spearman test for OA grading of femorotibial joints (KL) with cartilage defects on ultrasound showed a significant positive correlation with $p$ value $=0.002$ with correlation coefficients $($ rho $)=0.459$. The median value of cartilage defect in first grade OAwas 1 , second grade OA was 1 , third grade OA was 3 , and fourth grade OA 4 was 3 , can be seen in Figure 5.

Figure 5. Scatter Graph of femorotibia Joint (KL) OA Grading and Cartilage Defects.

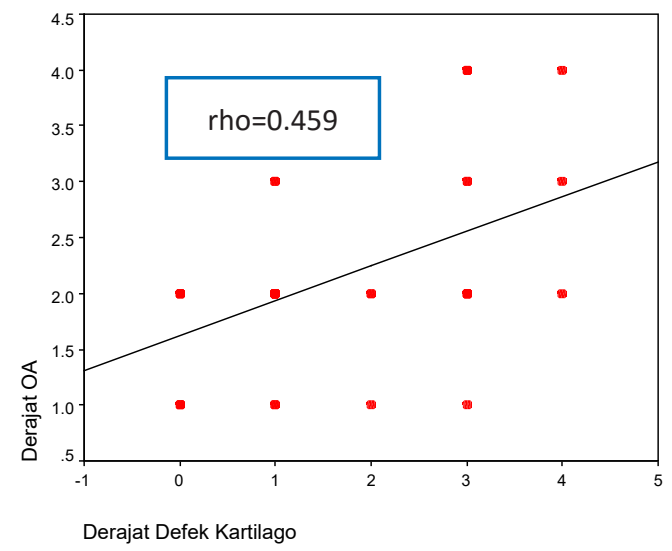

\section{Discussion}

In this study the number of women is more than men. This is consistent with the fact that women have risk factors of knee OA rather than men. M. Blagojevic, et al. (2010), performed a cohort, case-control study stated that women are more susceptible than men. ${ }^{15}$ Yuqing Zhang, et al. (2004) suggested that the long squat activity is a strong risk factor of the occurrence of knee OA in old people. ${ }^{16}$

Analysis correlations of OA grading in femorotibial joints and BMI have no significant relationship ( $\mathrm{p}>0.05)$. Velandai, et al. in 2005 with population based study stated that women in age $\geq 55$ years tend to be exposed more severe than men. ${ }^{17}$ While, Shiozaki H, et al. study, a 14 years longitudinal study (1979-1993) in 1191 women concluded that patients with overweight and obesity at the initial survey may have higher risk to developed OA and higher risk of knee OA progression if OA has developed before. ${ }^{18}$ Reijman M (2006) study, concluded that higher BMI increases the incidence of knee $\mathrm{OA}(\mathrm{OR} 3.3)$ and is associated with knee OA progression (OR 3.2) . $^{19}$

Subjects mostly have normal femorotibia alignment, 33 of 43 joints (76.7\%); and Varus and valgus account for 10 joints
$(23.3 \%)$. However, malalignment and OA grading have no significant correlation ( $p>0.05$ ). In the other hand, Sharma L, et al. (2010) cohort study mentioned that the knee joint with varus and valgus alignment have increased OA progression. ${ }^{20}$ Moreover, Teichtahl AJ, et al. (2006) study stated that varus alignment associated with the risk of narrowing of the medial compartment joints $(\mathrm{p}<0.001)$ and valgus alignment associated with the risk of narrowing of the lateral compartment joints ( $p$ $<0.001) .{ }^{21}$ In addition, joints malalignment can also be affected by disease duration and type of work. Unfortunately, we have not performed any analysis of joint malalignment in patients based on disease duration and type of work.

In this study, the degree of pain, stiffness and resistance activity in OA grade 1 is higher than OA grade 2,3, and 4. This study is consistent with Link TM, et al. (2002) and Cubukcu D, et al. (2012) that stated no significant relationship between KL and WOMAC score $(\mathrm{p}>0.05) .{ }^{10,22}$ Dieppe PA and Lohmander $\mathrm{S}$ (2005) mentioned that the pain is influenced by many factors, such as biochemical pathways (cytokines, proteases), location and severity of OA, as well as psychosocial and socioeconomic factors ie. comorbid diabetes, hypertension, coronary heart disease, kidney failure, gastrointestinal bleeding, depression, impaired physical and obesitas. ${ }^{23}$ While, Brandt KD, et al. (1998) told that pain is caused by few sources, include periosteal stretching, osseous hypertension, microfracture subchondral, ligament strain, enthesopathy, bursitis, hypertension intraarticular, instability of the joint capsule and ischemia sinovium. ${ }^{24}$ Additionally, some of our subjects had received physiotherapy and analgesics which might influence the pain measurement.

In this study, most subjects were suffered by first grade cartilage defects $(39.5 \%)$. Obesity and joints abnormalities are factors that influence abnormal pressure on the joints and lead to cartilage damage. In this study, we found no significant relationship between cartilage defects grade with BMI and joint malalignment $(\mathrm{p}>0.05)$. Consistently with Tuck Davies, et al. (2008) study, which mentioned that BMI was not associated with cartilage defects $(p=0.60$ for cartilage defect in the medial tibiofemoral and $p=0.92$ for the lateral tibiofemoral cartilage defects). ${ }^{25}$ Janakiramanan $\mathrm{N}$, et al. (2006) concluded that the change of $1^{\circ}$ towards genu valgum in patients with osteoarthritis would decrease the risk of medial tibial cartilage defects (OR 0.86), but increase the risk of lateral tibial cartilage defects (OR 1.06). ${ }^{26}$

Thickness of the cartilage on the medial side is $0.18 \mathrm{~cm}$, trochlear side is $0.20 \mathrm{~cm}$ and the lateral side is $0.17 \mathrm{~cm}$. However, Iagnocco A (2010) study stated that the average of cartilage thickness is $3 \mathrm{~mm}^{8}$ Moreover, measurement of cartilage thickness in this study is also different from the research conducted by Kazam, et al. in USA (2011). In that study, the average thickness on medial side was 0.23 $\mathrm{cm}$, trochlea side was $0.31 \mathrm{~cm}$ and the lateral side was 0.22 $\mathrm{cm}$. Differences in cartilage thickness can be caused by the different posture of the USA and Indonesian people. ${ }^{27}$

McNemar test are based on the suitability of the results of the examination with $\mathrm{p}>0.05$, the kappa test obtained value of $\mathrm{k}=0.714$ which showed high conformity between cartilage defects locations on USG and narrowing of femorotibial 
joints on X Ray. Spearman Rank test between OA grading on femorotibial joints (KL) by X-ray with cartilage defect grading on ultrasonography showed a significant positive correlation with $\mathrm{p}$ value 0.002 with correlation coefficients (rho) 0.459 . The median value in cartilage defect of the first and second grade OA were 1, while the median value of the cartilage defect of the third and fourth degree were 3. This is consistent with Link TM, et al (2002) cross-sectional study that assessed the correlation of KL with cartilage lesions on MRI. That study concluded that the degree of cartilage lesions on MRI increases with increased KL scores (rho $=0: 55$, p $<0.01){ }^{10}$

\section{CONCLUSION}

There is a significant positive correlation between OA grading in femorotibial joints $(\mathrm{KL})$ with cartilage defects grading assesed by ultrasonography. It can be implied that a cartilage defect grading by ultrasonography has the same diagnostic value with an X-ray imaging to measure OA grading by KL scoring system. Cartilage defects in the knee joint can affect radiographic changes. The osteophytes trigger defects in cartilage though improved power transmission and cartilage defect causes a narrowing of the joint. ${ }^{28}$

\section{References}

1. Lozada CJ. Management of Osteoarthritis. In: Firestein GS, Kelley WN, editor. Kelley's Textbook of Rheumatology, $8^{\text {th }}$ ed. Philadelphia: Saunders Elsevier; 2009:1563-1577.

2. Mabey T, Honsawek S. Cytokines as biochemical markers for knee osteoarthritis. World J Orthop. 2015; 6(1): 95-105.

3. Arya RK, Jain V. Osteoarthritis of the knee joint: An overview. JIACM. 2013; 14(2): 154-162.

4. Cesare PE, Abramson SB, Samules J. Pathogenesis of Osteoarthritis. In : Firestein GS, Kelley WN, editor. Kelley's Textbook of Rheumatology, $8^{\text {th }}$ ed. Philadelphia: Saunders Elsevier; 2009:1525-1546.

5. Soeroso J, Isbagio H, Kalim H, Broto R, Pramudiyo R. Osteoartritis. In : Sudoyo AW, Setiyohadi B, Alwi I, Simadibrata M, Setiati S, editors. Buku Ajar IImu Penyakit Dalam. $4^{\text {th }}$ ed. Jakarta: Pusat penerbitan Departemen IImu Penyakit Dalam FK Ul; 2006:1205-1211.

6. Putra TR. Osteoartritis lutut. Proceedings of Pendidikan Kedokteran Berkelanjutan XI IImu Penyakit Dalam FK Unud/RS Sanglah. Bali; 2003:1617.

7. Aigner T, Schmitz N. Pathogenesis and pathology of osteoarthritis [Internet]. In: Hochberg M, Silman A, Smolen J, Weinblatt M, Weisman $M$, editors. Rheumatology, 5th edition. Philadelphia: Mosby Elsevier; 2011: 1741-1759. [Cited Mei 2016] Available from : https://www.med. unc.edu/tarc/events/eventfiles/Hichberg\%20text.\%200A\%20 path.pdf.

8. lagnocco A. Osteoarthritis. In : Essential application of Musculoskeletal ultrasound In Rhematology. Philadelphia: Saunders Elsevier; 2010: 165179.

9. Kellgren JH, Lawrence JS. Radiological assessment of osteoarthrosis. Ann Rheum Dis 1957;16:494-502.

10. Link TM, Steinbach LS, Ghosh S, Ries M, Lu Y, Lane N, at all. Osteoarthritis: MR Imaging Findings in Different Stages of Disease and Correlation with
Clinical Findings. Radiology. 2003 Feb;226(2):373-381

11. Buckwalter JA, Mankin HJ. Articular cartilage: degeneration and osteoarthritis, repair, regeneration, and transplantation. Instr Course Lect 1998; 47:487-504

12. Buckwalter JA, Mankin HJ. Articular cartilage, part II: degeneration and osteoarthritis, repair regeneration, and transplantation. J Bone Joint Surg. 1997 Apr; 79A(4):612-630.

13. Aula AS, Töyräs J, Tiitu V, Jurvelin JS. Simultaneous ultrasound measurement of articular cartilage and subchondral bone. Osteoarthritis Cartilage. 2010 Dec; 18(12):1570-1576.

14. Buckwalter JA, Martin J. Degenerative joint disease. Clin Symp. 1995; 47(2):1-32.

15. Blagojevic M, Jinks $C$, Jeffery $A$, Jordan KP. Risk factors for onset of osteoarthritis of the knee in older adults: a systematic review and metaanalysis. Osteoarthritis Cartilage. 2010 Jan; 18 (1):24-33.

16. Zhang Y, Hunter DJ, Nevitt MC, at all. Association of squatting with increased prevalence of radiographic tibiofemoral knee osteoarthritis: the Beijing Osteoarthritis Study. Arthritis Rheum.2004 April; 50 (4) :11871192.

17. Srikanth VK, Fryer JL, Zhai G, at all. A meta-analysis of sex differences prevalence, incidence and severity of osteoarthritis.Osteoarthritis Cartilage. 2005Sep;13(9):769-81.

18. Shiozaki H, Koga Y, Tamaki M. Obesity and osteoarthritis of the knee in women: results from the matsudai knee osteoarthritis survey. The Knee. 1999;6(8):189-192.

19. Reijman M, Pols HA, Hazes JMW, Belo JN, Lievense AM, Zeinstra S. Body mass index associated with onset and progression of osteoarthritis of the knee but not of the hip: The Rotterdam Study. Ann Rheum Dis. 2007 Feb;66 (2):158-162.

20. Sharma L, Song J, Dunlop D, Felson D, Lewis CE, Segal N, at all. Varus and Valgus Alignment and Incident and Progressive Knee Osteoarthritis. Ann Rheum Dis. 2010 November ; 69(11): 1940-1945.

21. Teichtahl AJ. Cicuttini FM, Janakiramanan N, Wluka AE. Brief report Static knee alignment and its association with radiographic knee osteoarthritis. OsteoArthritis and Cartilage. 2006 Sept; 14 (9):958-962.

22. Cubukcu D, Sarsan A, Alkan H. Clinical Study Relationships between Pain, Function and Radiographic Findings in Osteoarthritis of the Knee: A Cross-Sectional Study [Internet]. Arthritis. 2012; ID: 984060. doi:10.1155/2012/984060.

23. Dieppe, PA and Lohmander, LS. Pathogenesis and management of pain in osteoarthritis. Lancet.2005 Mar; 365 (9463): 965-973.

24. Suntoko B. Penatalaksanaan dan Diagnostik Osteoartritis Sendi Lutut. In Proceeding book of PKB VI PAPDI Cabang Makasar. 2014 October.

25. Tuck M, Wluka AE, Wang Y, Teichtahl AJ, Jones G, Ding C, at all. The natural history of cartilage defects in people with knee osteoarthritis. Osteoarthritis and Cartilage. 2008 Mar; 16 (3): 337-342.

26. Janakiramnan N, Teichtahl AJ, Wluka AE. Ding C, Jones G, Davis SR, at all. Static Knee Alignment Is Associated with the Risk of Unicompartmental Knee Cartilage Defects. J. Orthop Res. 2008 Feb; 26(2): 225-230.

27. Kazam JK, Nazarian LN, Miller TT, Sofka CM, Parker L, Adler RS. Sonographic evaluation of femoral trochlear cartilage in patients with knee pain. J Ultrasound Med. 2011 June; 30(6): 797-802.

28. Ding C, Garnero P, Cicuttini F, Scott F, Cooley H, Jones G. Knee cartilage defects: association with early radiographic osteoarthritis, decreased cartilage volume, increased joint surface area and type II collagen breakdown. Osteoarthritis and Cartilage. 2005; 13(3):198-205. 